\title{
Ring-closing-metathesis-based synthesis of annellated coumarins from 8-allylcoumarins
}

\author{
Christiane Schultze and Bernd Schmidt ${ }^{\star}$
}

\section{Full Research Paper}

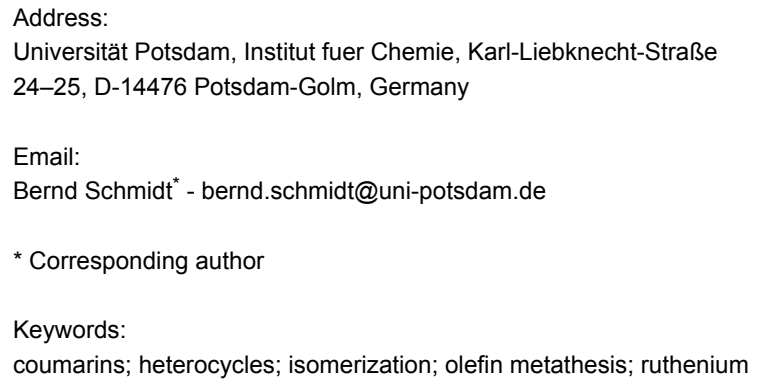

Beilstein J. Org. Chem. 2018, 14, 2991-2998. doi:10.3762/bjoc. 14.278

Received: 13 September 2018

Accepted: 22 November 2018

Published: 05 December 2018

This article is part of the thematic issue "Progress in metathesis chemistry III".

Guest Editors: K. Grela and A. Kajetanowicz

(C) 2018 Schultze and Schmidt; licensee Beilstein-Institut.

License and terms: see end of document.

\begin{abstract}
8-Allylcoumarins are conveniently accessible through a microwave-promoted tandem Claisen rearrangement/Wittig olefination/ cyclization sequence. They serve as a versatile platform for the annellation of five- to seven-membered rings using ring-closing olefin metathesis (RCM). Furano-, pyrano-, oxepino- and azepinocoumarins were synthesized from the same set of precursors using $\mathrm{Ru}$-catalyzed double bond isomerizations and RCM in a defined order. One class of products, pyrano[2,3-f $]$ chromene-2,8-diones, were inaccessible through direct RCM of an acrylate, but became available from the analogous allyl ether via an assisted tandem catalytic RCM/allylic oxidation sequence.
\end{abstract}

\section{Introduction}

Naturally occurring coumarins and synthetic derivatives have attracted considerable attention, because many of these compounds are pharmacologically active [1-4]. Their activity profiles are quite diverse and range from anticoagulant via antiinfective, anticancer to antineurodegenerative activities [2,3]. The majority of natural coumarins are secondary metabolites isolated from plants [5-7]. A commonly used taxonomy for these natural products (which has been extended to the nonnatural analogues) is based on the coumarin structure (Figure 1) $[4,8]$.
It distinguishes between simple coumarins with substituents only at the benzene part (e.g., osthole, a natural product with $\mathrm{Ca}^{2+}$-channel antagonist activity) [9], coumarins with substituents at the pyrone part (e.g., warfarin, a synthetic clinically used anticoagulant) [10], and heteroannellated coumarins, in which a heterocycle is annellated to the benzene ring of the coumarin skeleton. In particular the latter group is often further divided into sections according to ring size (five-membered rings: furanocoumarins; six-membered rings: pyranocoumarins) and location of the annellated ring (linear vs angular). Angelicin (3a, 


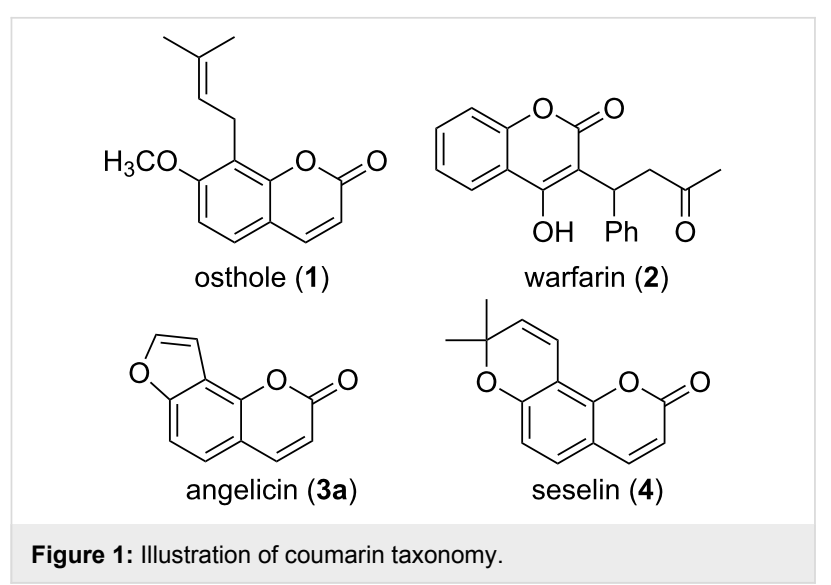

also named isopsoralen), for instance, is an angular furanocoumarin from Psoralea corylifolia $[11,12]$ that is moderately cytotoxic [13] and exhibits anti-oxidative activity [14], but is significantly less phototoxic than the linear isomer psoralen, due to its inability to cross link DNA [15]. This consideration has, for example, led to the development of substituted angelicins rather than psoralens as potential anti-influenza drugs [16]. Seselin (4) is an example of an angular pyranocoumarin found in various plants, e.g., from the family of Rutaceae [17] Among other bioactivities, the compound itself and some natural and non-natural derivatives induce apoptosis in melanoma HTB-140 cells [18].

Synthetic approaches to substituted coumarins in general and heteroannellated coumarins [19] in particular can start from other naturally occurring coumarins [20] or may involve the construction of the coumarin skeleton. For the latter group of syntheses several classical methods, such as the Perkin condensation, are available, which have been covered in earlier reviews $[5,6,8]$. Unfavorable reaction conditions, low yields and a sometimes limited scope make the development of alternatives to these established methods necessary. Examples from the past 15 years include transition metal-catalyzed transformations [21-23], solid-phase synthesis directed at combinatorial library design [24] and organocatalytic annellation reactions $[25,26]$.

Sparked by our interest in the development and application of sequential one-pot transformations and motivated by the relevance of prenylated and other substituted coumarins in natural products and medicinal chemistry, we [27-29] and others [30] have investigated a microwave-promoted tandem reaction for the synthesis of 8-substituted coumarins over the past few years. Starting materials are allyl ethers of salicylic aldehydes or ketones 5 and the stable ylide ethyl (triphosphoranylidene)acetate (6), which upon microwave irradiation undergo a tandem Claisen rearrangement/Wittig olefination/cyclization sequence. This sequence was pioneered by the groups of Harwood $[31,32]$ and Mali [33-36], and its Wittig olefination/cyclization part has been employed in the synthesis of various coumarins without alkyl substituents at position 8 [37-39]. In all previous reports conventional heating was used to induce the tandem sequence.

In this contribution we report how 8-allylcoumarins obtained through the microwave-promoted tandem sequence can be elaborated into heteroannellated coumarins that are either natural products or close ring-expanded analogues, using ring-closing olefin metathesis (RCM) reactions. Precedence for the use of RCM [40] in the synthesis and functionalization of coumarins is scarce, considering the vast number of applications olefin metathesis has found [41] and taking into account the high relevance of coumarins. Construction of the coumarin by RCM has been reported by few groups [42-45] and heteroannellations to the coumarin scaffold based on RCM are also limited in number and have mostly not been surveyed systematically [46-53].

\section{Results and Discussion}

To study the heteroannellation reactions, a set of four 8-allyl-7hydroxycoumarins 8 were synthesized starting from the MOMprotected precursors $\mathbf{5 a}-\mathbf{d}$ using the conditions of the microwave-promoted tandem sequence [29]. The intermediate MOMprotected coumarins were not isolated but immediately deprotected by treatment with aq $\mathrm{HCl}$ in methanol. Isolation of the MOM-protected coumarins 7 [29] and deprotection in a separate step resulted in virtually identical overall yields of coumarins $\mathbf{8}$ and did therefore not offer any advantage (Table 1).

For the synthesis of furanocoumarins $\mathbf{3}$ and their ring-expanded oxepino analogues 11 the 8-allylcoumarins 8 were first O-allylated. The resulting allyl ethers 9 underwent ring-closing metathesis to oxepines 11 smoothly in the presence of second-generation Grubbs' catalyst A [54] within one hour at $90{ }^{\circ} \mathrm{C}$, except for the 4-phenyl-substituted derivative $\mathbf{9 b}$, which was recovered from the reaction mixture under these conditions. However, compound $9 \mathrm{~b}$ was successfully cyclized to $\mathbf{1 1 b}$ using catalyst $\mathbf{A}$ in dichloromethane at ambient temperature, higher dilution and after prolonged reaction time. For the synthesis of furanocoumarins 3 the allyl ethers 9 were first subjected to a $\mathrm{Ru}$ hydride-catalyzed double bond isomerization $[55,56]$ to furnish enol ethers $\mathbf{1 0}$ as inseparable mixtures of diastereoisomers. For these reasons a complete structural assignment turned out to be difficult, but the products with a 7-Z-propenyloxy- and an 8-E-propenyl substituent, as shown in Table 2, were in all cases predominant, followed by the $E, E$-configured products. The ratio of these two isomers was ca. 3:1 for compounds 10a,b,d and ca. 10:1 for 10c with an adjacent coordinating methoxy group. The other two diastereoisomers were present only in trace amounts. 
Table 1: Synthesis of 8-allyl-7-hydroxycoumarins 8.

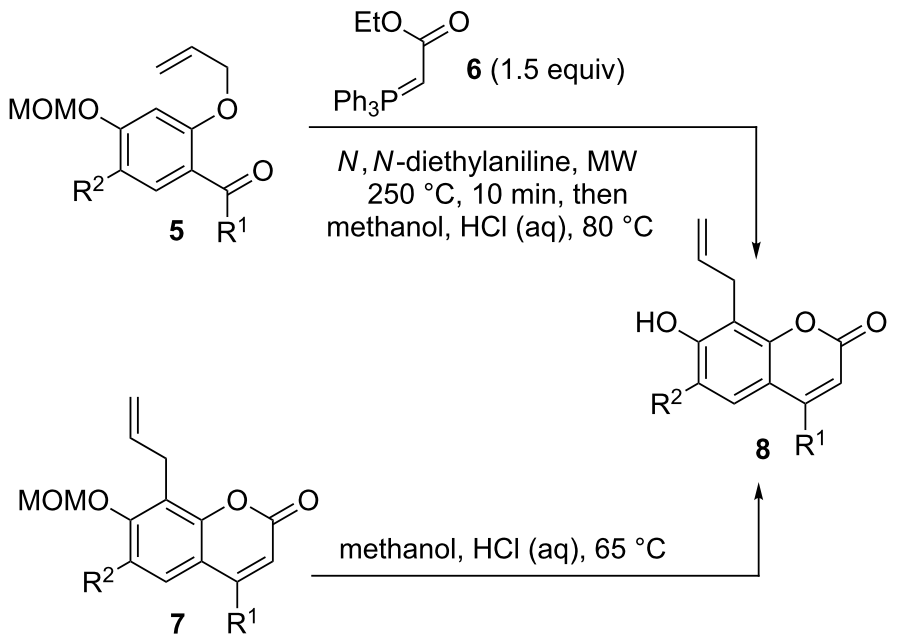

\begin{tabular}{lllllll}
\hline entry & $\mathbf{5}$ & $\mathrm{R}^{1}$ & $\mathrm{R}^{2}$ & $\mathbf{8}$ & yield (\%) & ${\text { yield }(\%)^{\mathrm{b}}}^{\mathrm{b}}$ \\
\hline 1 & $\mathbf{5 a}$ & $\mathrm{H}$ & $\mathrm{H}$ & $\mathbf{8 a}$ & 59 & 82 \\
2 & $\mathbf{5 b}$ & $\mathrm{C}_{6} \mathrm{H}_{5}$ & $\mathrm{H}$ & $\mathbf{8 b}$ & 70 & 91 \\
3 & $\mathbf{5 c}$ & $\mathrm{H}$ & $\mathrm{OCH}_{3}$ & $\mathbf{8 c}$ & 40 & 84 \\
4 & $\mathbf{5 d}$ & $\mathrm{CH}_{3}$ & $\mathrm{H}$ & $\mathbf{8 d}$ & 66 & 89 \\
\hline
\end{tabular}

aYield starting from 5 without isolation of 7 . bYield starting from 7 .

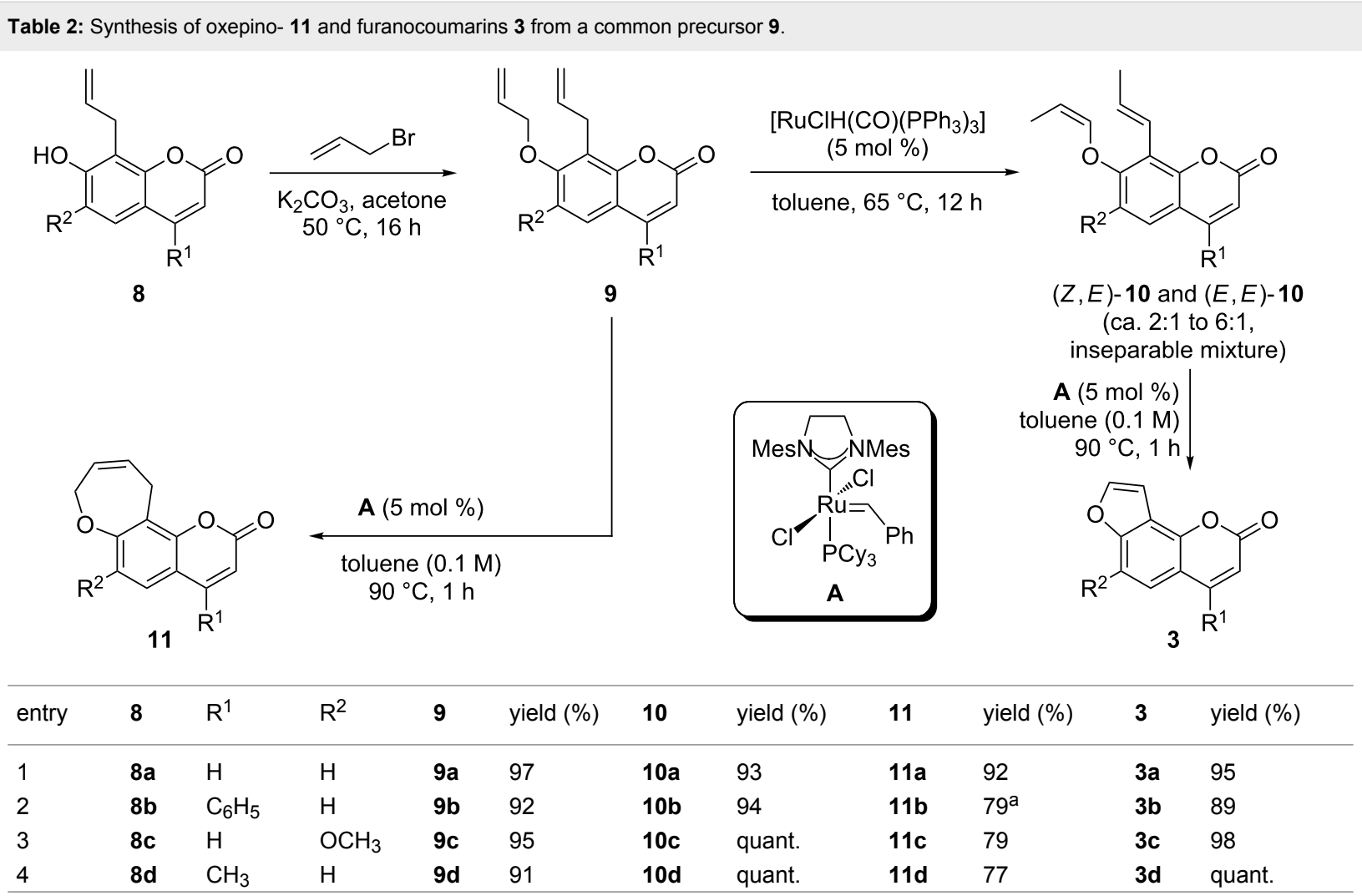

${ }^{\mathrm{a}} \mathbf{A}(5 \mathrm{~mol} \%), \mathrm{CH}_{2} \mathrm{Cl}_{2}(0.05 \mathrm{M}), 20^{\circ} \mathrm{C}$. 
RCM of enol ethers [57,58] $\mathbf{1 0}$ under the same conditions used for the synthesis of the oxepino-annellated coumarins $\mathbf{1 1}$ gave furanocoumarins 3 in excellent yields (Table 2). Furanocoumarins 3a (angelicin or isopsoralen, Table 2, entry 1) $[11,12]$ and $3 \mathbf{c}$ (sphondin, Table 2, entry 3) $[59,60]$ are natural products. They have previously been synthesized from 7-hydroxy-8-iodocoumarins through Sonogashira coupling and cyclization [61] or via Dötz benzannellation [62] of furanyl carbene complexes and acetylenes [63]. Angelicin (3a) was also obtained via RCM of 8-(1-propenyl)-7-vinyloxycoumarin, but the synthesis of this precursor required four steps, starting from umbelliferone, and proceeded only with moderate regioselectivity for the second step [47].

Next, we investigated the synthesis of coumarins with annellated unsaturated lactones starting from the same 8-allylcoumarins 8 (Scheme 1). For the synthesis of oxepin-2-oneannellated coumarins 13 compounds $\mathbf{8}$ were first converted to the corresponding acrylates $\mathbf{1 2}$ with acryloyl chloride (Table 3). RCM of these acrylates turned out to be not straightforward but required some optimization (Table 4).

In particular, a reduced initial substrate concentration of $0.01 \mathrm{M}$ and reaction temperatures of $110^{\circ} \mathrm{C}$ (Table 4, entry 6) led to a smooth conversion to the desired oxepin-2-ones $\mathbf{1 3}$, whereas ambient or slightly elevated temperatures in $\mathrm{CH}_{2} \mathrm{Cl}_{2}$ or toluene as a solvent (Table 4, entries 1,2 and 5) resulted in incomplete conversions and low yields. Addition of the Lewis acid $\mathrm{Ti}(\mathrm{OiPr})_{4}$, which had previously been reported to prevent the formation of inactive catalyst-substrate chelates [64], inhibited the RCM reaction completely in this case (Table 4, entries 3 and 4). The beneficial effect of low initial substrate concentrations on RCM reactions with acrylates has previously been described [65] and was later systematically investigated by one of us [66].

A possible access to the pyran-2-one-annellated coumarin substitution pattern 15 was investigated starting from acrylate 12d

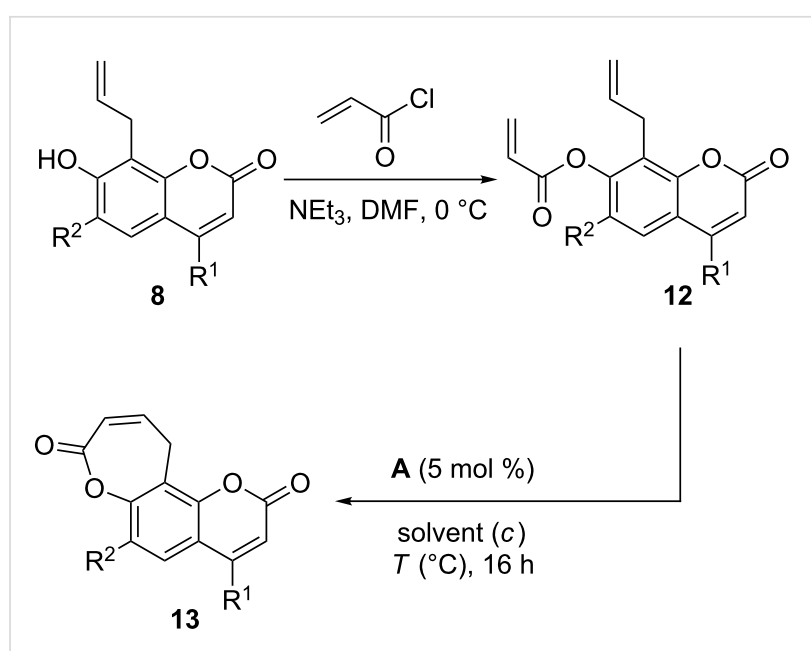

Scheme 1: Synthesis of oxepin-2-one-annellated coumarins 13 by RCM of acrylates 12.

\begin{tabular}{llllll}
\multicolumn{5}{l}{ Table 3: Synthesis of acrylates $\mathbf{1 2}}$. \\
entry & $\mathbf{8}$ & $\mathrm{R}^{1}$ & $\mathrm{R}^{2}$ & $\mathbf{1 2}$ & yield (\%) \\
\hline 1 & $\mathbf{8 a}$ & $\mathrm{H}$ & $\mathrm{H}$ & $\mathbf{1 2 a}$ & 92 \\
2 & $\mathbf{8 b}$ & $\mathrm{C}_{6} \mathrm{H}_{5}$ & $\mathrm{H}$ & $\mathbf{1 2 b}$ & 93 \\
3 & $\mathbf{8 c}$ & $\mathrm{H}$ & $\mathrm{OCH}_{3}$ & $\mathbf{1 2 c}$ & 89 \\
4 & $\mathbf{8 d}$ & $\mathrm{CH}_{3}$ & $\mathrm{H}$ & $\mathbf{1 2 d}$ & 86
\end{tabular}

(Scheme 2). The isomerization of the 8-allyl substituent to a prop-1-enyl substituent under the conditions used for the synthesis of precursors 10 (Table 2) stopped at 50\% conversion. Higher catalyst loading and an increased reaction temperature, however, resulted in a quantitative conversion to $\mathbf{1 4 d}$ as a mixture of $E$ - and $Z$-isomers. Although the RCM of similarly substituted acrylates to coumarins was previously described in the literature, this reaction failed completely for the envisaged synthesis of $\mathbf{1 5 d}$ from $14 \mathbf{d}$ under various conditions. Initial substrate concentrations varying from $0.01 \mathrm{M}$ to $0.10 \mathrm{M}$, the sol-

\begin{tabular}{|c|c|c|c|c|c|c|c|c|}
\hline entry & 12 & $\mathrm{R}^{1}$ & $\mathrm{R}^{2}$ & solvent & $c\left(\mathrm{~mol} \cdot \mathrm{L}^{-1}\right)$ & $T\left({ }^{\circ} \mathrm{C}\right)$ & 13 & yield $(\%)$ \\
\hline 1 & $12 a$ & $\mathrm{H}$ & $\mathrm{H}$ & $\mathrm{CH}_{2} \mathrm{Cl}_{2}$ & 0.05 & 20 & $13 a$ & 16 \\
\hline 2 & $12 a$ & $\mathrm{H}$ & $\mathrm{H}$ & $\mathrm{CH}_{2} \mathrm{Cl}_{2}$ & 0.01 & 40 & $13 a$ & 35 \\
\hline $3^{a}$ & $12 a$ & $\mathrm{H}$ & $\mathrm{H}$ & $\mathrm{CH}_{2} \mathrm{Cl}_{2}$ & 0.01 & 40 & $13 a$ & $-^{b}$ \\
\hline $4^{c}$ & $12 a$ & $\mathrm{H}$ & $\mathrm{H}$ & $\mathrm{CH}_{2} \mathrm{Cl}_{2}$ & 0.01 & 40 & $13 a$ & $-\mathrm{b}$ \\
\hline 5 & $12 a$ & $\mathrm{H}$ & $\mathrm{H}$ & toluene & 0.01 & 20 & $13 a$ & 20 \\
\hline 6 & $12 a$ & $\mathrm{H}$ & $\mathrm{H}$ & toluene & 0.01 & 110 & $13 a$ & 81 \\
\hline 7 & $12 b$ & $\mathrm{C}_{6} \mathrm{H}_{5}$ & $\mathrm{H}$ & toluene & 0.01 & 110 & $13 b$ & 79 \\
\hline 8 & $12 c$ & $\mathrm{H}$ & $\mathrm{OCH}_{3}$ & toluene & 0.01 & 110 & $13 c$ & 91 \\
\hline 9 & $12 d$ & $\mathrm{CH}_{3}$ & $\mathrm{H}$ & toluene & 0.01 & 110 & $13 d$ & 86 \\
\hline
\end{tabular}

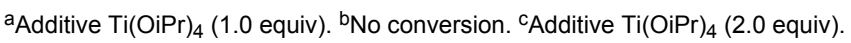




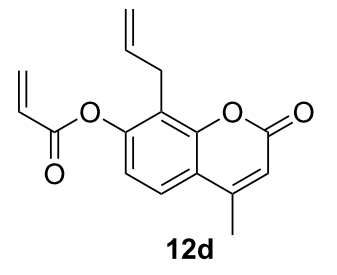

$\left[\mathrm{RuClH}(\mathrm{CO})\left(\mathrm{PPh}_{3}\right)_{3}\right]$ $(8 \mathrm{~mol} \%)$

toluene, $110{ }^{\circ} \mathrm{C}, 12 \mathrm{~h}$<smiles>C=CC(=O)Oc1ccc2c(C)cc(=O)oc2c1C=CC</smiles><smiles>Cc1cc(=O)oc2c1ccc1oc(=O)ccc12</smiles>

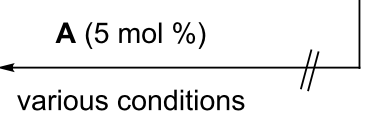

$15 d$

Scheme 2: Attempted synthesis of pyran-2-one-annellated coumarin $15 \mathrm{~d}$ via isomerization-RCM.

vents dichloromethane and toluene, and reaction temperatures between ambient temperature and $110{ }^{\circ} \mathrm{C}$ were tested, but to no avail.

As a method to circumvent notoriously difficult acrylate RCM steps we [45] and others [67] have developed an assisted tandem catalytic [68] RCM/allylic oxidation sequence. Such tandem sequences are characterized by the combination of two mechanistically distinct catalytic reactions in a defined order, which proceed with a single precatalyst that undergoes a transformation in situ upon addition of a suitable reagent, a "chemical trigger" [69]. In the case of the RCM/allylic oxidation sequence tert-butyl hydroperoxide is added after completion of the metathesis reaction, which most likely induces a conversion of the metathesis active $\mathrm{Ru}$-carbene species to a Ru(IV)-oxo species. The latter are known to catalyze allylic and benzylic oxidation reactions through a radical mechanism [70].

To implement this tandem sequence in the synthesis of pyran-2one-annellated coumarins $\mathbf{1 5}$ an isomerization of the 8-allyl substituent to a prop-1-enyl substituent was first required. When 8-allyl-7-hydroxycoumarin (8a) was subjected to the isomerization conditions previously used for the synthesis of furanocoumarin precursors $\mathbf{1 0}$ (see Table 2) we observed no conversion. A plausible explanation is the formation of a stable sixmembered $\mathrm{Ru}-\mathrm{O}-$ chelate complex following hydroruthenation, which inhibits a subsequent $\beta$-hydride elimination and thus interrupts the catalytic cycle. For these reasons we started from the MOM-protected 8-allylcoumarins 7, which underwent the Ru-hydride catalyzed double bond migration smoothly. The MOM group was cleaved off without isolation of the intermediate products and the required 7-hydroxy-8-(prop-1enyl)coumarins 16 were isolated in high overall yields and $E$-selectivities. Allylation of phenols $\mathbf{1 6}$ furnished the RCM pre- cursors 17, which underwent the tandem RCM/allylic oxidation sequence to compounds $\mathbf{1 5}$ in fair yields (Table 5). All pyran-2one-annellated coumarins $\mathbf{1 5}$ synthesized in the course of this study were previously described in the literature: compound 15a was used to investigate the regioselectivity of [2+2]-photocycloadditions [71], compound $\mathbf{1 5 d}$ was included in a comparative investigation into the fluorescence properties of 4-methylcoumarins [72], compounds $\mathbf{1 5 b}$ and $\mathbf{1 5 c}$ were tested for bacteriostatic activity [73] and insect-antifeedant activity [74], respectively. A common denominator of these reports is that a thorough investigation into the spectral and biological properties of these compounds is hampered by unsatisfactory yields and selectivities if classical coumarin syntheses are used. Compound 15a, for instance, was obtained in only 14\% yield from umbelliferone and malic acid in a Pechmann synthesis [71].

We concluded our study by investigating the possibility to transfer the syntheses of oxa-annellated coumarins described above to the aza-annellated derivatives. Starting point was the 7-acetamido-substituted coumarin 18 [29], which was first $\mathrm{N}$-allylated to the allylamide 19. Dual double bond migration was accomplished with the $\mathrm{Ru}$-hydride complex used previously and furnished the enamide 20 in high yield and predominantly as the $E, E$-isomer. In light of previous work by Arisawa et al. [75], who reported a synthesis of indoles by RCM of sterically less encumbered enamides, we investigated the RCM of 20. Unfortunately, no conversion to the indole 22 could be observed under various conditions. Ring-closing metathesis of $\mathbf{1 9}$ was, in contrast, successful and furnished the azepinocoumarin 21 in quantitative yield (Scheme 3).

\section{Conclusion}

In summary, we demonstrated that annellated coumarins become accessible from appropriately substituted benzene 
Table 5: Synthesis of pyran-2-one-annellated coumarins 15 via tandem RCM/allylic oxidation.<smiles>C=CCc1c(O)ccc2ccc(=O)oc12</smiles>

$8 a$<smiles>[R]c1cc2c([R])cc(=O)oc2c(CC=C)c1OC</smiles>

2) methanol, $\mathrm{HCl}(\mathrm{aq}), 65^{\circ} \mathrm{C}$

$\left[\mathrm{RuClH}(\mathrm{CO})\left(\mathrm{PPh}_{3}\right)_{3}\right]$

toluene, $65^{\circ} \mathrm{C}, 12 \mathrm{~h}$
1) $\left[\mathrm{RuClH}(\mathrm{CO})\left(\mathrm{PPh}_{3}\right)_{3}\right]$

$(5 \mathrm{~mol} \%)$, toluene, $65^{\circ} \mathrm{C}, 12 \mathrm{~h}$<smiles>[R]c1cc2c([R])cc(=O)oc2c(C)c1O</smiles>
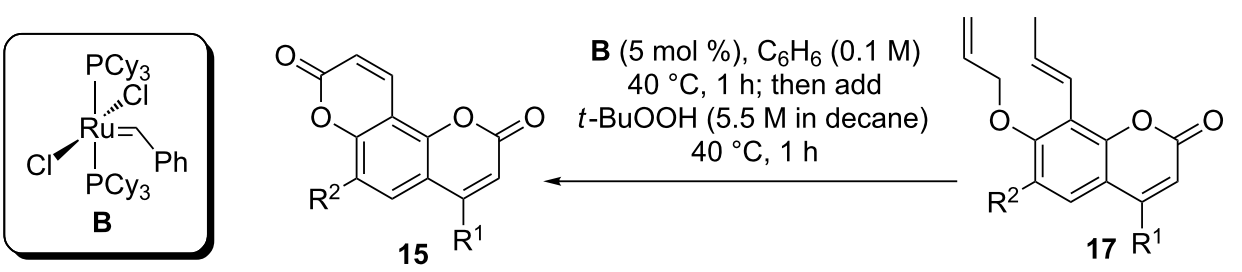

\begin{tabular}{llllllllll}
\hline entry & $\mathbf{7}$ & $\mathrm{R}^{1}$ & $\mathrm{R}^{2}$ & $\mathbf{1 6}$ & yield (\%) & $\mathbf{1 7}$ & yield (\%) & $\mathbf{1 5}$ & yield (\%) \\
\hline 1 & $\mathbf{7 a}$ & $\mathrm{H}$ & $\mathrm{H}$ & $\mathbf{1 6 a}$ & 95 & $\mathbf{1 7 a}$ & 93 & $\mathbf{1 5 a}$ & 56 \\
2 & $\mathbf{7 b}$ & $\mathrm{C}_{6} \mathrm{H}_{5}$ & $\mathrm{H}$ & $\mathbf{1 6 b}$ & 81 & $\mathbf{1 7 b}$ & 89 & $\mathbf{1 5 b}$ & 41 \\
3 & $\mathbf{7 c}$ & $\mathrm{H}$ & $\mathrm{OCH}_{3}$ & $\mathbf{1 6 c}$ & quant. & $\mathbf{1 7 c}$ & 90 & $\mathbf{1 5 c}$ & 45 \\
4 & $\mathbf{7 d}$ & $\mathrm{CH}_{3}$ & $\mathrm{H}$ & $\mathbf{1 6 d}$ & 92 & $\mathbf{1 7 d}$ & quant. & $\mathbf{1 5 d}$ & 47
\end{tabular}<smiles>C=CCc1c(NC=C)ccc2c(C)cc(=O)oc12</smiles>

18

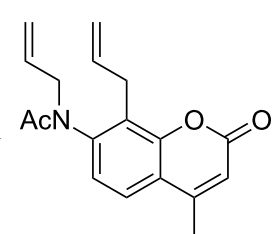

19 (quant.)

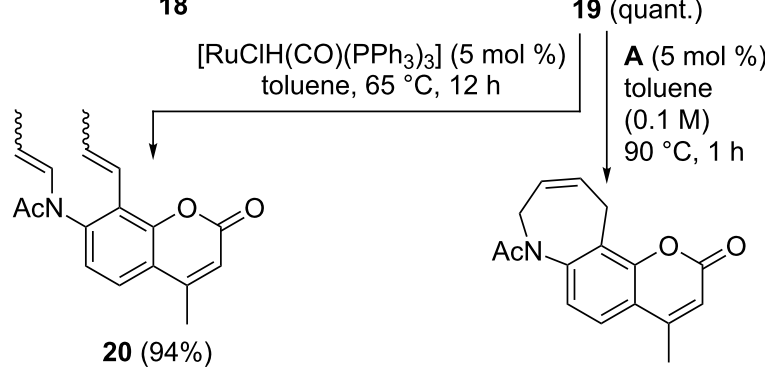

$20(94 \%)$

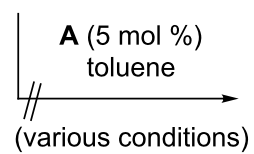<smiles>Cc1cc(=O)oc2c1ccc1c2ccn1C(C)(C)C</smiles>

Scheme 3: Synthesis of aza-annellated coumarin 21 and attempted synthesis of indole 22. derivatives in few steps, using a microwave-promoted tandem Wittig olefination/Claisen rearrangement/cyclization sequence for the construction of the 8-allylcoumarin scaffold and combinations of double bond isomerization and ring-closing olefin metathesis for the annellation of a second heterocycle. Pyran-2-one-annellated coumarins, which are scarcely available in synthetically useful yields through classical methods, became accessible through a tandem RCM/allylic oxidation sequence.

\section{Supporting Information}

\section{Supporting Information File 1}

Full experimental procedures, characterization data and copies of ${ }^{1} \mathrm{H}$ and ${ }^{13} \mathrm{C}$ NMR spectra of all compounds. [https://www.beilstein-journals.org/bjoc/content/ supplementary/1860-5397-14-278-S1.pdf]

\section{Acknowledgements}

We thank Evonik Oxeno for generous donations of solvents and Umicore (Hanau, Germany) for generous donations of catalysts. 


\section{ORCID ${ }^{\circledR}$ iDs}

Bernd Schmidt - https://orcid.org/0000-0002-0224-6069

\section{References}

1. Kulkarni, M. V.; Kulkarni, G. M.; Lin, C.-H.; Sun, C.-M. Curr. Med. Chem. 2006, 13, 2795-2818. doi:10.2174/092986706778521968

2. Riveiro, M. E.; De Kimpe, N.; Moglioni, A.; Vazquez, R.; Monczor, F.; Shayo, C.; Davio, C. Curr. Med. Chem. 2010, 17, 1325-1338. doi:10.2174/092986710790936284

3. Peng, X.-M.; Damu, G. L. V.; Zhou, C.-H. Curr. Pharm. Des. 2013, 19, 3884-3930. doi:10.2174/1381612811319210013

4. Venugopala, K. N.; Rashmi, V.; Odhav, B. BioMed Res. Int. 2013, No. 963248. doi:10.1155/2013/963248

5. Murray, R. D. H. Nat. Prod. Rep. 1995, 12, 477-505. doi:10.1039/np9951200477

6. Murray, R. D. H. Prog. Chem. Org. Nat. Prod. 2002, 83, 1-673.

7. Sarker, S. D.; Nahar, L. Progress in the Chemistry of Naturally Occurring Coumarins. In Progress in the Chemistry of Organic Natural Products; Kinghorn, A. D.; Falk, H.; Gibbons, S.; Kobayashi, J., Eds.; Springer International Publishing: Cham, 2017; Vol. 106, pp 241-304. doi:10.1007/978-3-319-59542-9_3

8. Keating, G. J.; O'Kennedy, R. The Chemistry and Occurance of Coumarins. In Coumarins - Biology, Applications and Mode of Action; O'Kennedy, R.; Thornes, R. D., Eds.; Wiley: Chichester, 1997; pp 23-66.

9. Fusi, F.; Sgaragli, G.; Ha, L. M.; Cuong, N. M.; Saponara, S. Eur. J. Pharmacol. 2012, 680, 22-27. doi:10.1016/j.ejphar.2012.01.038

10. Kleemann, A.; Engel, J.; Kutscher, B.; Reichert, D. Pharmaceutical substances, 5th ed.; Georg Thieme Verlag: Stuttgart; New York, 2009. doi:10.1055/b-003-108611

11. Innocenti, G.; Cappelletti, E. M.; Caporale, G. Int. J. Pharmacogn. (Lisse, Neth.) 1991, 29, 311-316. doi:10.3109/13880209109082905

12. Won, T. H.; Song, I.-H.; Kim, K.-H.; Yang, W.-Y.; Lee, S. K.; Oh, D.-C.; Oh, W.-K.; Oh, K.-B.; Shin, J. J. Nat. Prod. 2015, 78, 666-673. doi:10.1021/np500834d

13. Mar, W.; Je, K.-H.; Seo, E.-K. Arch. Pharmacal Res. 2001, 24 211-213. doi:10.1007/bf02978259

14. Seo, E.; Lee, E.-K.; Lee, C. S.; Chun, K.-H.; Lee, M.-Y.; Jun, H.-S. Oxid. Med. Cell. Longevity 2014, No. 897296. doi:10.1155/2014/897296

15. Bethea, D.; Fullmer, B.; Syed, S.; Seltzer, G.; Tiano, J.; Rischko, C.; Gillespie, L.; Brown, D.; Gasparro, F. P. J. Dermatol. Sci. 1999, 19, 78-88. doi:10.1016/s0923-1811(98)00064-4

16. Yeh, J.-Y.; Coumar, M. S.; Horng, J.-T.; Shiao, H.-Y.; Kuo, F.-M.; Lee, H.-L.; Chen, I.-C.; Chang, C.-W.; Tang, W.-F.; Tseng, S.-N.; Chen, C.-J.; Shih, S.-R.; Hsu, J. T.-A.; Liao, C.-C.; Chao, Y.-S.; Hsieh, H.-P. J. Med. Chem. 2010, 53, 1519-1533. doi:10.1021/jm901570x

17. Gunatilaka, A. A. L.; Kingston, D. G. I.; Wijeratne, E. M. K.; Bandara, B. M. R.; Hofmann, G. A.; Johnson, R. K. J. Nat. Prod. 1994, 57, 518-520. doi:10.1021/np50106a013

18. Ostrowska, K.; Olejarz, W.; Wrzosek, M.; Głuszko, A.; Nowicka, G.; Szczepański, M.; Materek, I. B.; Kozioł, A. E.; Struga, M. Biomed. Pharmacother. 2017, 95, 1412-1424. doi:10.1016/j.biopha.2017.09.050
19. Medina, F. G.; Marrero, J. G.; Macías-Alonso, M.; González, M. C. Córdova-Guerrero, I.; Teissier García, A. G.; Osegueda-Robles, S. Nat. Prod. Rep. 2015, 32, 1472-1507. doi:10.1039/c4np00162a

20. Maes, D.; Syngel, K. V.; Debenedetti, S.; De Kimpe, N. Tetrahedron 2006, 62, 4426-4429. doi:10.1016/j.tet.2006.02.055

21. Priyanka; Sharma, R. K.; Katiyar, D. Synthesis 2016, 48, 2303-2322. doi:10.1055/s-0035-1560450

22. Kang, D.; Ahn, K.; Hong, S. Asian J. Org. Chem. 2018, 7, 1136-1150. doi:10.1002/ajoc.201800128

23. Kitamura, T.; Otsubo, K. J. Org. Chem. 2012, 77, 2978-2982. doi:10.1021/jo300021a

24. Nicolaou, K. C.; Pfefferkorn, J. A.; Roecker, A. J.; Cao, G.-Q.; Barluenga, S.; Mitchell, H. J. J. Am. Chem. Soc. 2000, 122, 9939-9953. doi:10.1021/ja002033k

25. Modrocká, V.; Veverková, E.; Baran, R.; Šebesta, R. ChemistrySelect 2018, 3, 1466-1471. doi:10.1002/slct.201800147

26. Cheng, Y.; Zhang, P.; Jia, Y.; Fang, Z.; Li, P. Org. Biomol. Chem. 2017, 15, 7505-7508. doi:10.1039/c7ob01730h

27. Schmidt, B.; Riemer, M. Synthesis 2016, 48, 141-149. doi:10.1055/s-0035-1560501

28. Schmidt, B.; Schultze, C. Eur. J. Org. Chem. 2018, 223-227. doi:10.1002/ejoc.201701684

29. Schultze, C.; Schmidt, B. J. Org. Chem. 2018, 83, 5210-5224. doi:10.1021/acs.joc.8b00667

30. Konrádová, D.; Kozubíková, H.; Doležal, K.; Pospišil, J. Eur. J. Org. Chem. 2017, 5204-5213. doi:10.1002/ejoc.201701021

31. Cairns, N.; Harwood, L. M.; Astles, D. P. J. Chem. Soc., Chem. Commun. 1986, 1264-1266. doi:10.1039/c39860001264

32. Cairns, N.; Harwood, L. M.; Astles, D. P. J. Chem. Soc., Perkin Trans. 1 1994, 3101-3107. doi:10.1039/p19940003101

33. Mali, R. S.; Manekar, A. R.; Tilve, S. G. Indian J. Chem., Sect. B: Org. Chem. Incl. Med. Chem. 1987, 26, 1007. 34. Mali, R. S.; Joshi, P. P.; Sandhu, P. K.; Manekar-Tilve, A. J. Chem. Soc., Perkin Trans. 1 2002, 371-376. doi:10.1039/b109597h 35. Patre, R. E.; Shet, J. B.; Parameswaran, P. S.; Tilve, S. G. Tetrahedron Lett. 2009, 50, 6488-6490. doi:10.1016/j.tetlet.2009.09.017

36. Patre, R. E.; Parameswaran, P. S.; Tilve, S. G. ARKIVOC 2011, No. ix, 68-76. doi:10.3998/ark.5550190.0012.905

37. Ishii, H.; Ishikawa, T.; Wada, H.; Miyazaki, H.; Kaneko, Y.; Harayama, T. Chem. Pharm. Bull. 1992, 40, 2614-2619. doi:10.1248/cpb.40.2614

38. Maes, D.; Riveiro, M. E.; Shayo, C.; Davio, C.; Debenedetti, S.; De Kimpe, N. Tetrahedron 2008, 64, 4438-4443. doi:10.1016/j.tet.2008.02.059

39. Demyttenaere, J.; Vervisch, S.; Debenedetti, S.; Coussio, J.; Maes, D.; De Kimpe, N. ChemInform 2004, 35, 1844-1848. doi:10.1002/chin.200452188

40. Schmidt, B.; Hauke, S.; Krehl, S.; Kunz, O. Ring-Closing Metathesis. In Comprehensive Organic Synthesis II, 2nd ed.; Molander, G. A.; Knochel, P., Eds.; Elsevier: Amsterdam, 2014; pp 1400-1482. doi:10.1016/b978-0-08-097742-3.00530-9

41. Grela, K., Ed. Olefin Metathesis - Theory and Practice; John Wiley \& Sons: Hoboken, 2014. doi:10.1002/9781118711613

42. Chatterjee, A. K.; Toste, F. D.; Goldberg, S. D.; Grubbs, R. H. Pure Appl. Chem. 2003, 75, 421-425. doi:10.1351/pac200375040421

43. Nguyen Van, T.; Debenedetti, S.; De Kimpe, N. Tetrahedron Lett. 2003, 44, 4199-4201. doi:10.1016/s0040-4039(03)00902-x 
44. Polito, L.; Cravini, M.; Poletti, L.; Lay, L. Synth. Commun. 2006, 36, 2203-2209. doi:10.1080/00397910600638937

45. Schmidt, B.; Krehl, S. Chem. Commun. 2011, 47, 5879-5881. doi:10.1039/c1cc11347j

46. Chattopadhyay, S. K.; Maity, S.; Panja, S. Tetrahedron Lett. 2002, 43, 7781-7783. doi:10.1016/s0040-4039(02)01806-3

47. Tsai, T.-W.; Wang, E.-C. J. Chin. Chem. Soc. 2004, 51, 1019-1023. doi:10.1002/jccs.200400152

48. Majumdar, K. C.; Muhuri, S.; Rahaman, H.; Islam, R.; Roy, B. Chem. Lett. 2006, 35, 1430-1431. doi:10.1246/cl.2006.1430

49. Majumdar, K. C.; Samanta, S.; Chattopadhyay, B.; Nandi, R. K. Synthesis 2010, 863-869. doi:10.1055/s-0029-1218620

50. Litinas, K. E.; Mangos, A.; Nikkou, T. E.; Hadjipavlou-Litina, D. J. J. Enzyme Inhib. Med. Chem. 2011, 26, 805-812. doi:10.3109/14756366.2011.555944

51. Chattopadhyay, S. K.; Mondal, P.; Ghosh, D. Synthesis 2014, 46, 3331-3340. doi:10.1055/s-0034-1379141

52. Yerrabelly, J. R.; Chakravarthula, V.; Yerrabelly, H.; Chitneni, P. R.; Batchu, V. R.; Nanubolu, J. B.; Krishnan, R. K. Tetrahedron Lett. 2015, 56, 2180-2182. doi:10.1016/j.tetlet.2015.02.106

53. Goud, E. Y.; Rao, B. K.; Thirupahi, G.; Hemasri, Y.; Rao, C. P.; Kumar, P. V.; Rao, Y. J. ChemistrySelect 2017, 2, 1170-1174. doi:10.1002/slct.201601614

54. Scholl, M.; Ding, S.; Lee, C. W.; Grubbs, R. H. Org. Lett. 1999, 1, 953-956. doi:10.1021/ol990909q

55. Krompiec, S.; Kuźnik, N.; Penczek, R.; Rzepa, J.; Mrowiec-Białoń, J. J. Mol. Catal. A: Chem. 2004, 219, 29-40. doi:10.1016/j.molcata.2004.04.039

56. Kúznik, N.; Krompiec, S. Coord. Chem. Rev. 2007, 251, 222-233. doi:10.1016/j.ccr.2006.07.006

57. van Otterlo, W. A. L.; Morgans, G. L.; Madeley, L. G.; Kuzvidza, S.; Moleele, S. S.; Thornton, N.; de Koning, C. B. Tetrahedron 2005, 61, 7746-7755. doi:10.1016/j.tet.2005.05.090

58. Schmidt, B.; Wolf, F. J. Org. Chem. 2017, 82, 4386-4395. doi:10.1021/acs.joc.7b00447

59. Coassini Lokar, L. R.; Delben, S. Phytochemistry 1988, 27 , 1073-1077. doi:10.1016/0031-9422(88)80276-0

60. O'Neill, T.; Johnson, J. A.; Webster, D.; Gray, C. A. J. Ethnopharmacol. 2013, 147, 232-237. doi:10.1016/j.jep.2013.03.009

61. Sardari, S.; Mori, Y.; Horita, K.; Micetich, R. G.; Nishibe, S.; Daneshtalab, M. Bioorg. Med. Chem. 1999, 7, 1933-1940. doi:10.1016/s0968-0896(99)00138-8

62. Dötz, K. H. Angew. Chem., Int. Ed. Engl. 1984, 23, 587-608. doi:10.1002/anie.198405871

63. Wulff, W. D.; McCallum, J. S.; Kunng, F. A. J. Am. Chem. Soc. 1988, 110, 7419-7434. doi:10.1021/ja00230a023

64. Fürstner, A.; Langemann, K. J. Am. Chem. Soc. 1997, 119, 9130-9136. doi:10.1021/ja9719945

65. Ghosh, A. K.; Cappiello, J.; Shin, D. Tetrahedron Lett. 1998, 39, 4651-4654. doi:10.1016/s0040-4039(98)00887-9

66. Schmidt, B.; Geißler, D. Chem CatChem 2010, 2, 423-429. doi:10.1002/cctc.200900282

67. Kato, H.; Ishigame, T.; Oshima, N.; Hoshiya, N.; Shimawaki, K.; Arisawa, M.; Shuto, S. Adv. Synth. Catal. 2011, 353, 2676-2680. doi:10.1002/adsc.201100303

68. Fogg, D. E.; dos Santos, E. N. Coord. Chem. Rev. 2004, 248, 2365-2379. doi:10.1016/j.ccr.2004.05.012

69. Schmidt, B.; Krehl, S. Domino and Other Olefin Metathesis Reaction Sequences. In Olefin Metathesis - Theory and Practice; Grela, K., Ed.; Wiley: Hoboken, 2014; pp 187-232. doi:10.1002/9781118711613.ch5
70. Murahashi, S.-I.; Komiya, N.; Oda, Y.; Kuwabara, T.; Naota, T. J. Org. Chem. 2000, 65, 9186-9193. doi:10.1021/jo001348f

71. Bethke, J.; Margaretha, P.; Wynne, A. M.; Caldwell, R. A. J. Chem. Res. 1998, 142-143. doi:10.1039/a707819f

72. Maruyama, J.; Ito, K. Chem. Pharm. Bull. 1984, 32, 1178-1182. doi:10.1248/cpb.32.1178

73. Raju, M. S.; Subba Rao, N. V. Proc. - Indian Acad. Sci., Sect. A 1974, 79, 223-229. doi:10.1007/bf03051323

74. Nagaiah, K.; Krupadanam, G. L. D.; Srimannarayana, G. Indian J. Chem., Sect. B: Org. Chem. Incl. Med. Chem. 2002, 41, 858-862.

75. Arisawa, M.; Terada, Y.; Takahashi, K.; Nakagawa, M.; Nishida, A. J. Org. Chem. 2006, 71, 4255-4261. doi:10.1021/jo060308u

\section{License and Terms}

This is an Open Access article under the terms of the Creative Commons Attribution License

(http://creativecommons.org/licenses/by/4.0). Please note that the reuse, redistribution and reproduction in particular requires that the authors and source are credited.

The license is subject to the Beilstein Journal of Organic Chemistry terms and conditions: (https://www.beilstein-journals.org/bjoc)

The definitive version of this article is the electronic one which can be found at: doi:10.3762/bjoc. 14.278 